\title{
Engineering Students Perspective on Mentoring and Leadership
}

\section{Diana Bairaktarova, Purdue University, West Lafayette}

Diana Bairaktarova is a doctoral candidate in the School of Engineering Education at Purdue University. She holds B.S. and M.S. degrees in Mechanical Engineering from Technical University at Sofia, Bulgaria and an M.B.A. from Hamline School of Business at St. Paul, Minnesota. Bairaktarova has over a decade of experience working as a design engineer. Her research is focused on human learning and engineering (i.e. understanding how individual differences and aptitudes affect interaction with mechanical objects in engineering education instruction), and how engineering students' personality traits influence ethical decision making process in engineering design.

\section{Dr. Monica Farmer Cox, Purdue University, West Lafayette}

Dr. Monica F. Cox is an associate professor in the School of Engineering Education at Purdue University and is the inaugural director of the Engineering Leadership Minor. She obtained a B.S. in Mathematics from Spelman College, a M.S. in Industrial Engineering from the University of Alabama, and a Ph.D. in Leadership and Policy Studies from Peabody College of Vanderbilt University. Teaching interests relate to the professional development of graduate engineering students and to leadership, policy, and change in science, technology, engineering, and mathematics education. Primary research projects explore the preparation of engineering doctoral students for careers in academia and industry and the development of engineering education assessment tools. She is a National Science Foundation Faculty Early Career (CAREER) award winner and is a recipient of a Presidential Early Career Award for Scientists and Engineers (PECASE).

\section{Glen DePalma, Purdue University}

Glen DePalma is a Ph.D. candidate in the Department of Statistics at Purdue University.

\section{Ms. Pouneh Eftekhari}




\section{Engineering Students Perspective on Mentoring and Leadership}

This study was conducted to learn about students' perceptions on mentoring and leadership and to explore if there is a relationship between mentors' personality traits in regards to leadership and their beliefs of their own qualities as mentors and leaders. The hope is that understanding these relationships may improve course instruction and mentors experience. 49 students (peer mentors) taking the course Instruction, Mentorship, and Leadership completed a series of questionnaires. Along with the mentor's self-evaluation, mentors were also asked to submit mid-term evaluations addressing their strengths and weaknesses as peer mentors and what they might do to improve on their weaknesses. Results indicate that there is a discrepancy between peer mentors' selfassessments on mentoring, leadership skills and instruction performance and their peers' evaluation of mentors strengths and weaknesses. Our exploratory study also supported the linkages between the five dimensions of personality traits and leadership qualities. To help improve the course and mentors experience recommendations for further research are provided.

\section{INTRODUCTION}

The National Academy of Engineering (2005) suggested in Educating the Engineer of 2020 that: The future engineers have to be technically proficient engineers who are broadly educated, see themselves as global citizens, can be leaders in business and public service, and are ethically grounded ${ }^{[1]}$. The committee set targeted attributes needed for the graduates of 2020 . These include such traits as strong analytical skills, creativity, ingenuity, professionalism, and leadership. One of the few opportunities that undergraduate engineering students have to gain leadership skills and experience being on a leadership role at Purdue University is the course Instruction, Mentorship and Leadership. This one credit course is an elective course in the engineering curriculum designed to provide upper class engineering students with the training and information they will need to provide mentorship to incoming first-year engineering students, enabling them to successfully transition to their respective engineering departments within the College of Engineering. The goal of the course is to enable the upper class engineering students (peer mentors) to: facilitate first-year engineering students' successful achievement of Purdue University course goals; develop and apply effective teaching techniques to prepare, conduct, and evaluate a class; and develop and apply 
professional leadership skills in eight mentoring roles. The training sessions and class periods are designed to enable the peer mentors to achieve the course goals.

To register for the course, potential peer mentors first apply through the engineering student organization at the university. They are mainly chosen to serve as peer mentors based on their availability through the semester, membership in this organization, and their GPAs. Around 30\% of the students in the class are returning peer mentors. In these class sections, the instructor introduce course topics without going into great detail about each topic (i.e., 3 to 4 sections on instruction, 3 classes on mentorship, and 3 classes on leadership).

In order to improve instruction in engineering education, a study was conducted to learn about students' perceptions on mentoring and leadership before and after taking the course. The study investigates if there is a relationship between students' beliefs of their mentoring and leadership skills via evaluation of these skills from their peers and the course assessment.

The aim of this study is twofold- (1) to investigate the relationship between peer mentors' self assessments on mentoring, leadership skills and instruction performance and their peers' evaluation of mentors strengths and weaknesses, and (2) to explore a relationship between peer mentors' personality traits in regards to leadership and their beliefs of their own qualities as mentors and leaders.

\section{METHOD}

\subsection{Participants and Procedure}

Forty nine undergraduate engineering students taking the course, Instruction, Mentorship and Leadership, (ENGR 404) in the Fall semester at Purdue University in two separate sessions completed a series of questionnaires. Along with the peer mentor's self-evaluation, peer mentors were also asked to submit mid-term evaluations addressing their strengths and weaknesses as peer mentors and what they might do to improve on their weaknesses. Toward the end of the semester, the participants also completed personality test and ranked themselves in qualities of being a leader.

All surveys were taken in the beginning of the class sections. The median year in college was 3 (range 1 to 6 ). Twenty-one of the participants were female and twenty- 
eight were male. Thirteen of the participants were returning peer mentors from the last academic year.

\subsection{Instruments and study variables:}

\subsubsection{Pre and post survey}

A pre- and post survey was designed with 15 questions asking students to self assess their skills and experiences including their confidence on mentoring incoming first-year engineering students; developing and applying leadership skills in mentoring roles; and comfort level mentoring international students and engaging individuals from diverse backgrounds. The pre- and post surveys were taken at the beginning and end of the semester, respectively.

\subsubsection{Midterm self evaluation}

Along with the peer mentors' self-evaluations, peer mentors were also asked to submit mid-term evaluations addressing their strengths and weaknesses as a peer mentor and what they might do to improve on their weaknesses. Peer mentors were asked to write these evaluations as a summary of their incoming first-year student's responses to mid-term evaluation questions. Open-ended questions asked students to assess their peer mentors teaching or mentoring performance.

\subsubsection{Big Five Inventory (BFI)}

Leadership can be conceptualized and measured in different ways ${ }^{[3]}$ and can be separated into two broad categories: leadership emergence and leadership effectiveness

${ }^{[4]}$. Leadership emergence refers to whether an individual is viewed as a leader by others who typically have only limited information about that individual's performance. In contrast to being perceived as a leader, leadership effectiveness refers to a leader's performance in influencing and guiding the activities of his or her unit toward achievement of its goals ${ }^{[5]}$. The 44-item BFI scale ${ }^{[2]}$ measures five different dimensions of personality traits: neuroticism, extraversion, openness, agreeableness, and conscientiousness. Participants respond to each item on a 5-point scale (anchored with "strongly agree", and "strongly disagree"), such that higher scores indicate greater trait of the five different dimensions of these personalities.

\subsection{2. "How I rank myself in qualities of being a leader" ${ }^{[6]}$ questionnaire}


Students ranked themselves in qualities of being a leader responding to eight items: enthusiasm, prepared, communicates well with others, caring, creativity, problemsolver, character, adaptability, dependability, and cooperation. Participants responded to each item on a 4-point rating scale where 1 = "I need help how to do this", 2 = "I need to work on this", 3 = "I am pretty good at this", and 4 = "I definitely have this quality".

\subsection{Focus of the study}

The peer mentors are the primary contact with the first engineering students in the one credit seminar and they greatly influence these first-years students' academic experiences. In this study, we aimed to test how the peer mentors' perception, experience, and beliefs of mentorship and leadership relate to their abilities and personal qualities of being mentors and leaders.

We had the following hypotheses:

H1: There will be a discrepancy between peer mentors' self-assessments on mentoring, leadership skills and instruction performance and their actual performance

H2: There will be a relationship between peer mentors' personality traits in regards to leadership and their beliefs of their own qualities as mentors and leaders.

\section{RESULTS AND DISCUSSION}

\subsection{Results}

Overall the results from pre- and post- surveys showed that peer mentors' skills on instruction, mentoring, and leadership slightly improved after taking the class (Table 1). Students rated themselves very high on the pre-test which allowed for little improvement in the post test.

Table 1. Results from the course pre- and post-surveys

\begin{tabular}{l|c|c} 
& $\begin{array}{c}\text { Mean } \\
\text { Improvement } \\
\text { (post-pre) }\end{array}$ & Std Div \\
\hline $\begin{array}{l}\text { Confidently facilitate first-year engineering students' successful } \\
\text { achievement of ENGR 104 course goal }\end{array}$ & 0.533 & 0.786 \\
$\begin{array}{l}\text { Confidently develop and apply effective teaching techniques to } \\
\text { prepare, conduct, and evaluate a class }\end{array}$ & 0.577 & 0.916 \\
$\begin{array}{l}\text { Confident to develop and apply professional leadership skills in the } \\
\text { eight mentoring roles }\end{array}$ & 0.666 & 0.879
\end{tabular}


Confidently identify tools and resources to help me in my role as a Peer Mentor

Being a Peer Mentor motivates me to be professionally ethical

I chose the Peer mentoring role because I believe I am a leader

I am aware of cultural differences in the classroom (racial, sexual,

cultural) and know how to engage individuals from diverse backgrounds

I am comfortable giving constructive feedback to students in my class

I am comfortable addressing behavior issues in class

Half of the mentors were $100 \%$ confident in applying leadership skills in the mentoring roles, 16 mentors were $80 \%$ confident, 4 mentors reported around $50 \%$ confidence, and only one had a $20 \%$ confidence. However, when asked to list the eight peer mentor roles, only 14 mentors were able to list/describe 6 of the mentoring roles, 15 mentors knew 4 roles, and 15 (33\% of all responses) were not able to list/describe any mentoring roles.

Table 2 below shows the means and standard deviations of the mentors' knowledge of mentoring roles by their leadership skill level at both the beginning and end of the semester.

Table 2. Applying leadership skills in mentoring roles and knowledge of mentoring roles

\begin{tabular}{ccc}
$\begin{array}{c}\text { Leadership skills in mentoring } \\
\text { roles }\end{array}$ & $\begin{array}{c}\text { Pre-Knowledge of Mentoring } \\
\text { Roles }\end{array}$ & $\begin{array}{c}\text { Post-Knowledge of Mentoring } \\
\text { Roles }\end{array}$ \\
\hline $1-5$ Likert Scale $)$ & & - \\
2 & $1.00(0)$ & $0.71(0.71)$ \\
3 & - & $0.55(0.55)$ \\
4 & $0.50(1.00)$ & $1.06(0.80)$ \\
5 & $0.76(0.83)$ & $1.18(0.83)$
\end{tabular}

On a scale of 1 to 5 , the peer mentors rated their overall leadership skills high (mean $=4.44$, with 0.311 mean improvement from the beginning to the end of the class). Half of the peer mentors rated themselves as professionals with strong leadership skills. 
However, in their midterm reflections, the mentors hardly ever talk about mentorship and leadership. One out of 49 participants stated that having the opportunity to be a peer mentor has allowed her to grow as a leader. They didn't use any verbs such as "lead", "mentor", "instruct", or "guide". Only one peer mentor saw the reflections as an opportunity to continue practicing her strengths as a mentor and to grow in areas. Only one mentor stated that being able to work alongside the first-year engineering students and to pass on knowledge from the first-year has been a great way to give back to the community and the university.

Table 3 displays how the mentors ranked themselves in qualities of being a leader. It presents similar results as those in previous tables where mentors believe in their strong leadership skills. With the exception of creativity $($ mean $=2.89)$, where mentors shared that they need to work on expressing ideas, come up with helpful suggestions, and brainstorm new ideas compared to the rest of the leaders' qualities, the mentors again rank themselves very high in these qualities. However, even ranking themselves a little low on creativity, only one mentor shared as a weakness being not creative in the peer evaluation: "My main weakness is my lack of creativity with assignments and activities".

Table 3. How the mentors ranked themselves in qualities of being a leader

\begin{tabular}{l|c|c}
$\begin{array}{c}\text { Qualities of being } \\
\text { a leader }\end{array}$ & Mean & Std Dev \\
\hline Enthusiasm & 3.38 & 0.67 \\
Prepared & 3.34 & 0.72 \\
Communicate & 3.44 & 0.54 \\
Caring & 3.57 & 0.64 \\
Creativity & 2.89 & 0.82 \\
Problem-Solver & 3.53 & 0.54 \\
Character & 3.71 & 0.50 \\
Adaptability & 3.42 & 0.64 \\
Dependability & 3.67 & 0.51 \\
Cooperation & 3.42 & 0.57
\end{tabular}


In general, when peer mentors summarized their peers' evaluations on their strengths and weaknesses, the following theme emerged, which is in a conflict with the self-ranking above-

Communicate well with others (mean $=3.44$ ). Mentors rank themselves as effective speakers, being good with all kinds of people, tactful, and good listeners, but at the same time when evaluated by their peers, they are willing to share their weaknesses: "I get nervous when I am speaking in front of people", "I am stagnant and stand behind the podium", "I get easily distracted", "I get off-topic at times", "reducing the speed of my speeches is to make sure I know all of the details of what I am talking about", "I ramble on and talk too much, which means I don't give my peer mentor partner time to talk".

Although peer mentors believed they can assess a situation, understand the audience, know how to prepare, and know how to report, peer evaluations show that mentors are not well organized and do not always plan for class. Some of the mentors share their weaknesses: "I could also plan more with my peer mentor partner before class so that the class goes smoother and we touch on more topics in one class session", "I have to plan better in order to keep the class engaged and interested for the entire 50 minute period", "Something else that we can improve on is to be more efficient with our use of time because some students felt that we take too much time to cover some material”.

Mentors rank themselves high on enthusiasm $($ mean $=3.38)$, stating that they are very good at being motivated, with energy and a positive attitude. Peer evaluations, however, highlight something different: “My areas of weakness as a peer mentor include showing enthusiasm and excitement about the information. Showing more enthusiasm for the material we are discussing in class will be the best way for me to improve in my role as a mentor. Doing so will show the students that what we are talking about is important and my spark excitement in them”, "Give me a break, I don't need to come to class, we can communicate via e-mail”, " Let us go early, we will not violate the rules, it is only 1 credit course”, “ We don't get pay for teaching ENGR 104", "It is too early in the morning, can we take the section in the afternoon", "We have so much to do with our core courses", "I don't seem to take the class seriously", "I feel like I try to have a relaxed environment in the class to make it a break from their other classes but a 
feedback from one student says I should be slightly more serious", "I don't know the names of the students I am mentoring", "I can improve my acting a little bit sterner in discussions. The students said that I am very "chill" and too chill at times".

Giving instructions: "My weaknesses as a peer mentor are that I am not very skilled at being an instructor", "I have no experience with teaching or assigning homework, so I feel like there might be some awkward moments or questions that may go unanswered", I have difficulties grading - "I think in this way I might be "babying" some of them", "Another weakness is that it is sometimes hard to feel confident being in a mentoring or leadership role above people that are so close to me in age"

Table 4. Mentors comfort level of cultural diversity

\begin{tabular}{|c|c|c|c|}
\hline & $\begin{array}{l}\text { Domestic Students } \\
\qquad \mathrm{N}=40\end{array}$ & $\begin{array}{l}\text { International Students } \\
\qquad \mathrm{N}=5\end{array}$ & P-Value \\
\hline $\begin{array}{l}\text { Comfortable mentoring international } \\
\text { students }\end{array}$ & $3.20(.97)$ & $4.80(0.45)$ & $<.001$ \\
\hline Experience w/ different cultures & $3.70(0.939)$ & $4.60(0.54)$ & .015 \\
\hline $\begin{array}{l}\text { Aware of cultural differences in the } \\
\text { classroom (racial, sexual, cultural) and } \\
\text { know how to engage individuals from } \\
\text { diverse backgrounds }\end{array}$ & $4.00(0.99)$ & $4.80(0.45)$ & .010 \\
\hline
\end{tabular}

The majority of the peer mentors stated moderate comfort levels with regards to mentoring individuals from diverse backgrounds and addressing behavioral issues in class. The results in Table 4 above show that international students/mentors are more experienced with different cultures and are more confident mentoring international students. The awareness of cultural differences in the classroom (i.e., racial, sexual, cultural) is higher for international students, and they reported higher comfort level in knowing how to engage individuals from diverse backgrounds. Although only five mentors involved in the course were international students themselves, $40 \%$ of the first year engineering students enrolled in the ENGR 104 are foreign students.

The mentors' weaknesses discussed above could be also seen in their answers to the question "What leadership skill (s) did you developed after mentoring ENGR 104 students?" at the end of the semester. The most common skill the mentors stated they 
developed was communicating with others (12 responses), learning to plan and organize ( 9 responses), learning to be patient (7 responses), to control (3), be confident, be more diverse, open minded, encouraging, and responsible (2 responses for each), and to engage, to be flexible, to be fair, to be assertive (1 response for each).

All analyses support our first prediction that there will be a discrepancy between peer mentor's self assessment on mentoring, leadership skills and instruction performance, and their peers' evaluation of mentors' strengths and weaknesses.

To test the second hypothesis, we used Pearson correlation to assess the linear relationship between leadership qualities and personality traits.

Table 5. Relationship between Big Five Traits and Leadership Qualities

Leadership Qualities L
Agreeableness Conscientiousness

$$
\text { A }
$$

Extraversion Neuroticism

$\mathrm{E}$
$\mathrm{N}$
Openness

to Experience

\begin{tabular}{cccccc} 
& \multicolumn{3}{c}{$\mathrm{E}$} \\
\hline 1.0000 & 0.30358 & 0.22895 & 0.30277 & -0.27581 & 0.46615 \\
& 0.0340 & 0.1136 & 0.0345 & 0.0551 & 0.0007 \\
\hline
\end{tabular}

The results are shown in Table 5 show the correlations between the Big Five personality traits with leadership quality. The top number is the correlation while the bottom number is the p-value testing a difference from 0 . Overall, the correlations with Leadership were: Agreeableness $=.303$, Conscientiousness $=.228$, Extraversion $=.303$, Neuroticism $=-.275$, and Openness to Experience $=.466$. There was a positive association with leadership qualities for agreeableness, conscientiousness, extraversion, and openness to experience traits. There was a negative association between leadership qualities and neuroticism.

We investigated the relationship of the Big Five personality traits to leadership pooling across the leadership qualities. Conceptually, leadership qualities are distinct constructs. We have to also consider that the peer mentors self-rank themselves in these qualities and self-report their personality's traits. However, operationally, both are generally measured via ratings or observations of others, which means that both criteria represent individuals' perceptions of leadership. Because there is reason to believe that 
Neuroticism, Extraversion, and Openness will be related to multiple leadership criteria, we predicted that these traits will display significant (nonzero) relationships with leadership in the combined analysis.

We have also stratified the data by gender and mentoring experience but did not find significantly different results between groups. At the end of the semester, the peer mentors were asked if they would consider taking the course again next year. There were 41 positive responses with 12 mentors stating that they would like to take the opportunity of mentoring first-year students again but are graduating. One mentor said that he would like to explore more leadership roles somewhere else; one mentor claimed it is just too much work for a one credit course, and 6 mentors were not sure if their schedules would allow them to be peer mentors.

\section{CONCLUSIONS}

In order to improve the course instruction we attempted to learn about students' perceptions on mentoring and leadership and to explore if there is a relationship between mentors' personality traits in regards to leadership and their beliefs of their own qualities as mentors and leaders. The results of the analysis supported the first hypothesis that there will be a discrepancy between peer mentors' self-assessments on mentoring, leadership skills and instruction performance and their peers' evaluation of mentors strengths and weaknesses. Our exploratory study also supported the linkages between the five dimensions of personality traits and leadership qualities. Due to the small sample we did not address why these traits are relevant neither were we able to make any statistically significant claims. However raising this topic in this particular way we are hoping that, first: engineering educators and engineering student organizations responsible for maintaining a course with such settings to consider including different options of assessment of student knowledge and skills and evaluation of the course outcomes, and second: to find this information useful in defining specific objectives for course work within their programs, as they seek to prepare the future engineers of 2020 with complex attributes such as strong analytical skills, creativity, ingenuity, professionalism, and leadership. 


\section{Bibliography:}

[1] National Academy of Engineering, 2005. Committee on the engineer of 2020, Phase II. Committee on engineering education, educating the engineer of 2020: adapting engineering education to the new century. Washington, DC: The National Academies Press.

[2] John, O. P., \& Srivastava, S. (1999). The Big Five trait taxonomy: History, measurement, and theoretical perspectives. In L. A. Pervin, \& O. P. John (Eds.), Handbook of personality: Theory and research (pp.102-138). New York: Guilford Press.

[3] Hogan, R., Curphy, G. J., \& Hogan, J. (1994). What we know about leadership: Effectiveness and personality. American Psychologist, 49, 493-504.

[4] Lord, R. G., De Vader, C. L., \& Alliger, G. M. (1986). A meta-analysis of the relation between personality traits and leadership perceptions: An application of validity generalization procedures. Journal of Applied Psychology, 71, 402-410.

[5] Judge, T. A., Bono, J. E., Ilies, R., \& Gerhardt, M. W. (2002). Personality and leadership: A qualitative and quantitative review. Journal of Applied Psychology, 87, 765-780.

[6] Gilbertson A., Morreim P., Skelly C., Stevenson A. 10 -minutes Leadership Lessons. In the proceedings of National Conference of the National Association of Extension 4-H Agents Milwaukee, WI Oct. 23, 2006:

http://4h.missouri.edu/projects/curriculum/10minuteleadershiplessons.pdf Last retrieved 12/26/2012 